\title{
Opinião sobre AIDS e Possiveis Mudanças de Comportamento de Heterossexuais Masculinos
}

Sônia Maria Oliveira de Andrade *

O presente trabalho foi realizado com o objetivo de conhecer a opinião de uma amostra da população masculina, não-pertencente aos grupos de risco, a respeito da AIDS e as mudanças de comportamento sexual e social dela decorrentes, considerando-se as campanhas educativas, em Campo Grande, Mato Grosso do Sul. A coleta de dados foi feita através de questionários aplicados no período de 2 de janeiro a 14 de fevereiro de 1989, em 100 sujeitos. Após o levantamento , foram selecionados 98 questionários de elementos, cujo critério de escolha foi o de não se encontrarem enquadrados nos grupos clássicos de risco. $\mathrm{Da}$ análise dos dados conclui-se que, apesar de $60 \%$ dos entrevistados afirmarem haver modificado seus hábitos sexuais devido à AIDS, mais da metade dessa população optou por medidas ineficazes à prevenção da AIDS.

Ficou evidenciado, ainda, que existem hábitos sociais e culturais arraigados que vêm de encontro a medidas tais como: o uso de preservativos elou restrição à multiplicidade de parceiras, fato este que, associado à baixa eficácia das campanhas educativas atuais, apresentou-se como responsável pelas insuficientes medidas preventivas individuais. Como conclusão do trabalho, foi ressaltada a importância da reestruturação no conteúdo e na forma das campanhas educativas, a partir de pesquisas estratificadas que respaldem cientificamente a educação sanitária da população.

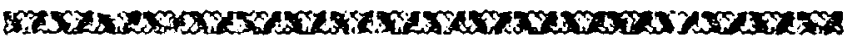

\section{INTRODUÇĀO}

A AIDS já atingiu 127 dos 159 países do mundo e a totalidade do território brasileiro, sendo, incontestavelmente, uma questão de saúde pública que exige

Cadernos de Saáde Póblica, RJ, 7(1): 45-68, jan/mar, 1991.
* Psicóloga. Coortenadora do Programa de Salide Mental da Secretaria de Estado da Saúde de Mato Grosso do Sul. Professora Auxiliar de Psicopatologia das Faculdades Unidas Católicas de Mato Grosso, Campo Grande, $M S$. 
um estudo continuado de todos os aspectos da ocorrência e propagação dessa pandemia, visando o seu controle.

Até o momento, embora estejam sendo feitas pesquisas exaustivas, não há vacina, cura ou tratamento para a AIDS, sendo possível apenas o tratamento dos sintomas das infecções que acometem o portador do HIV e as estratégias das campanhas educativas, que, além de essencialmente precisas, devem ser eficazes.

Analisando os dados estatísticos contidos em Boletins Informativos do Ministério da Saúde, verificamos que, enquanto de 1982 a 1984 o número de casos de AIDS na população heterossexual era de quatro, no biênio 1985-1987 o número foi elevado para 121, sendo que de 1988 até fevereiro de 1990 já eram 652 os casos notificados.

Decidimos investigar até que ponto essa população está sendo sensibilizada pelas campanhas educativas, evitando, através de mudança de comportamento sexual e social, a disseminação da infecção pelo HIV.

Além da preocupação com o aumento desses casos, tinha, e ainda tenho, algumas dúvidas com relaçăo à grande preocupação ética que se sobrepõe às medidas eficazes de controle sobre os indivíduos com soropositividade para o HIV e que podem ficar por anos na ignorância de sua infecção, ao mesmo tempo em que são agentes de transmissaao da AIDS. Outros, ainda que sabendo ter soropositividade para o HIV e recebendo todas as informaçōes acerca da doença e dos riscos, negam-se a ter os cuidados mínimos para evitar a transmissibilidade, sendo que, do ponto de vista epidemiológico, responsável pelas medidas de controle das epidemias, muito pouco se pode fazer, por questões éticas.

Reconhecemos que, devido à abrangência e magnitude de todas estas questões, apenas aquelas que dizem respeito aos números de casos de AIDS estavam afetas a nós, no que se refere à possibilidade de atuarmos no sentido de propor açōes educativas.

A partir daí, passaram a compor o eixo principal do trabalho indagações como:

- que mecanismos fazem com que, na certeza da iminência da morte, as pessoas não tomem precauçōes suficientes para se eximirem dos riscos?

- estas pessoas estão realmente conscientizadas do que seja a doença?

- até que ponto os órgãos de saúde pública, através das campanhas educativas, estão cumprindo a sua função de esclarecer e orientar?

Delimitamos um grupo de 100 heterossexuais, de Campo Grande, Mato Grosso do Sul, estratificados em dez grupos distintos, para responder a um questionário com perguntas abertas e fechadas, dizendo res- 
peito à sexualidade e sua relação com a AIDS, distribuídas em tópicos referentes às mudanças de comportamento sexual e às campanhas educativas.

Sobre esses tópicos e respaldado em opiniōes de população heterossexual é que este trabalho se baseou, e é na perspectiva de que venha a ser útil para a saúde pública que foi desenvolvido.

\section{Considerações sobre a AIDS}

\section{Histórico}

Sabe-se muito pouco sobre as origens da AIDS e menos ainda sobre a forma pela qual os primeiros portadores do vírus o disseminaram. $O$ que se sabe, de fato, é que os primeiros casos de AIDS surgiram aproximadamente na mesma época na África, Estados Unidos e Haiti, entre 1980 e 1981 (25), embora, examinando retrospectivamente os registros médicos, tenha sido possivel estabelecer que a AIDS, provavelmente, estava presente alguns anos antes, como um caso no Canadá, em 1979, e outros nos Estados Unidos, que remontam a outubro de 1978 (25).

\section{Etiologia e Transmissibilidade}

A descoberta do agente etiológico da AIDS ocorreu em 1983 (25), sendo que, até então, devido à variada sintomatologia, a única evidência que orientava os estudos era a de que se tratava de doença que lesa o sistema imunológico, pelo fato de todas as doenças apresentadas serem moderadamente indicativas de imunodeficiência celular, ou a elas associadas.

As pesquisas se direcionaram na busca de um vírus, dada a constatação dos sintomas decorrerem da destruição das células T. Franceses e americanos isolaram o vírus pela primeira vez em 1983, descobrindo que se tratava de retrovírus linfotrópico para linfócitos $T$ (25). Este vírus foi isolado em amostras de sangue, medula óssea, linfonodos, cérebro, plasma, saliva, sêmen e mucos cervicais de portadores do vírus da AIDS, embora só haja indícios de transmissão do HIV através do sangue, sêmen e secreçōes vaginais e cervicais. (17).

Devido a isso, consideram-se como categorias de transmissão:

- transmissão sexual - através de contatos homossexuais, heterossexuais e bissexuais;

- transmissão sangüínea - através de sangue e/ou hemoderivados e pelo uso de agulhas ou agulhas contaminadas; parto.

- transmissão peri-natal - antes ou durante o

Cadernos de Saude Pública, RJ, 7(1): 45-68, jan/mar, 1991. 
Tanto o Prof. Luc Montagnier, do Instituto Pasteur, quanto o grupo do Instituto Nacional de Câncer, de Maryland, liderado pelo Dr. Robert Gallo, se atribuem a descoberta do vírus. Considerando que os franceses utilizavam a sigla LAV (Vírus Associado à Linfadenopatia) e os americanos o nomeavam HTLV-III (Vírus Linfotrópico para Células T Humano), o Comitê Internacional para taxonomia de Vírus propôs a desig. nação HIV (Vírus da Imunodeficiência Humana) como denominação apropriada para o retrovínıs agente da AIDS, desde 1986 (15).

\section{Medidas de Controle Preconizadas pelo Ministério da Saúde}

O Ministério da Saúde, como medidas de controle da AIDS, preconiza uma série de açōes que devem ser executadas, como:

- notificação obrigatória de casos confirmados;

- investigação epidemiológica, através da identificação de grupos de risco, meios de transmissão e identificação de comunicantes;

- investigação clínica, pela confirmação do diagnóstico previamente estabelecido;

- educação Sanitária, com informação e orientação sobre os meios de diminuir a transmissibilidade da doença, sendo que esta educação deve enfatizar a possibilidade de transmissão através da prática sexual, instrumentos injetáveis contaminados, transmissão matemo-infantil e AIDS transfusional, para isso priorizando as medidas de prevenção individuais.

Para melhor compreensão das medidas de controle, o Ministério da Saúde considera:

\section{Caso confirmado}

a) Todo indivíduo que apresente doença moderadamente indicativa de imunodeficiência celular ou que apresente soropositividade para HIV, com presença de infecçöes, pneumonia intersticial linfóide crônica, neoplasias, desde que excluídas outras causas sabidamente associadas à diminuição da resistência, que não a infecção pelo HIV.

b) Indivíduo que, na ausência dos fatores citados acima, apresente, altemadamente ou em associação, as seguintes condições: complexo relacionado à AIDS (ARC) - soropositividade para o HIV $\left(^{*}\right)$, quando o vírus já lesou consideravelmente o sistema imunológico; presença de candidíase oral e/ou testes cutâneos de hipersensibilidade tardia negativos; presença de, pelo menos, três dos seguintes sinais ou sintomas:

Cadernos de Saŕde Pública, RJ, 7(1): 45-68, jan/mar, 1991. 
linfadenopatia generalizada, diarréia, febre, astenia, sudorese noturna, perda de peso superior a $19 \%$; ausência de outras causas sabidamente associadas à diminuição da resistência, que não a infecção pelo HIV.

\section{Caso suspeito}

Considera-se caso suspeito todo indivíduo soropositivo para o $\mathrm{HIV}$, que nấo se enquadre na definição de caso confirmado.

\section{Contato}

Parceiros (as) sexuais e filhos menores de um ano de idade, de casos confirmados de AIDS.

\section{Grupos de Risco}

Homossexuais masculinos, bissexuais masculinos, hemofilicos; receptores de transfusōes de sangue ocorridas nos últimos seis anos, usuários de drogas injetáveis; parceiros (as) sexuais de pessoas pertencentes aos grupos de risco e filhos nascidos de mães soropositivas.

\section{Críticas}

Os interesses da sociedade são absolutamente superiores aos interesses individuais, e entre uns e outros deve-se estabelecer uma relação justa e harmônica. Engels.

A desmitificação em torno da patologia da AIDS é um ponto relevante importante para o seu conhecimento, mas a indefinição de sua origem e a mutação do vírus nos deixam muito distantes de uma perspectiva otimista, na medida em que a realidade nos mostra que $50 \%$ dos portadores de HIV, possivelmente, desenvolverão a doença em até cinco anos, o que coloca o período de sobrevida do indivíduo infectado sempre aquém do prazo estimado pelos pesquisadores para possivel descobrimento de uma vacina, que é de dez anos (25).

Isso nos faz considerar que, diferentemente de outras doenças causadas por virus, são raríssimos os casos, ainda, de portadores de virus da AIDS que permaneceram vivos por mais de cinco anos (14).

Se analisarmos todos os dados de que dispomos, nāo há como considerar como "suspeito" um indivíduo soropositivo para o HIV, na medida em que se trata de infecção sem doença, com, portanto, maior potencial de transmissão e cujo controle epidemiológico deveria ser muito maior. Além do registro epidemiológico, seria necessário o acompanhamento em ambula-

Cadernos de Saúde Páblica, RJ, 7(1): 45-68, jan/mar, 1991. 
tório de atenção primária onde, além de receber orientação preventiva, seria objeto de investigação epidemiológica.

Nossa sugestão é a de que, para os individuos com soropositividade para HIV, seja considerada a sua inclusão em caso confirmado como infectado assin tomático, principalmente para que esta população seja alvo de investigação epidemiológica, visto que esta contempla casos de "doenças transmissíveis".

Acreditamos que, da mesma forma que o diagnóstico laboratorial da sífilis é o suficiente para que se considere o seu portador como doente contagiante (18), do ponto de vista epidemiológico, tal procedimento deva se dar com relação aos HIV positivos, principalmente considerando-se a taxa de letalidade dos portadores do HIV, a inexistência de recursos terapêuticos disponíveis e a progressão crescente do número de casos.

\section{Hipóteses e objetivo}

Há oito anos surge, oficialmente, a AIDS no Brasil e, como podemos constatar através do quadro I, sua transmissão se dá, por excelência, através dos contatos sexuais ( $77 \%$ dos casos), ou seja: a AIDS passa a vincular o sexo à morte e, à culpa intrínseca à sexualidade, soma-se o medo.

\section{QUADRO I}

Número e percentual de casos de AIDS em indivíduos com 15 ou mais anos de idade, por categoria de transmissão - Brasil $1980-1990$ (fev)

\begin{tabular}{lcr}
\hline Categoria de Transmissão & Número & $\%$ \\
\hline Transmissåo sexual & & \\
- contato homossexual & 4004 & 43,5 \\
- contato bissexual & 1906 & 20,7 \\
- contato heterossexual & 777 & 8,4 \\
Transmissăo sangǘnea & 1176 & 12,8 \\
- uso de drogas injetáveis & 192 & 2,1 \\
- hemofilia & 277 & 3,0 \\
- receptor de sangue/componentes & 874 & 9,5 \\
Transmissăo não-definida/outras & 9206 & 100,0 \\
\hline Total &
\end{tabular}

Fonte: Divisão Nacional de Doenças Sexualmente Transmissfveis - Serviço de Epidemiologia - Ministério da Saúde. 
Nossa hipótese de trabalho, considerando o aumento de casos de AIDS em heterossexuais masculinos, é a de que as campanhas educativas nāo estão sensibilizando a população acima referida a ponto de haver mudança no seu comportamento sexual e social visando evitar a disseminação da doença.

Nosso objetivo é avaliar a repercussão social da AIDS em determinada população heterossexual e, se possivel, propor algumas estratégias de ação, através da análise crítica do processo educativo, admitindo, conforme Miranda de Sá (19), que toda a existência pessoal de qualquer ser humano está permanentemente marcada pela ação simultânea e interaçāo recíproca de fatores biológicos, psicológicos e sociais, que as atitudes que se expressam na conduta (comportamento manifesto) nada mais são que uma predisposição para a prática de determinados atos, e esta se origina tanto em fatores biopsíquicos quanto em necessidades geradas socialmente, sejam culturais, sejam ligadas aos sistemas de produção e ainda que condicionamentos sociais determinam grande parte das condutas que influem de forma significativa na consciência humana. Realizamos este trabalho com o objetivo de avaliar a repercussão social da AIDS em determinada população heterossexual e propor algumas estratégias de ação, através da análise crítica do processo educativo.

\section{CONSIDERAÇŌES HISTÓRICAS}

A abordagem da questão da AIDS engloba, fundamentalmente, três aspectos básicos: sexualidade, relaçōes sociais e saúde pública, sendo que, para que possa haver uma compreensão da representação social da AIDS, é mister que se façam algumas consideraçōes sobre a relação entre os três fatores mencionados.

Quando Engels (6) afirma que a sexualidade do homem é uma necessidade incompleta e que tem de ser complementada em cada indivíduo pela aprendizagem que se realiza de acordo com as normas sociais, acrescenta uma outra consideração: a sociabilidade da sexualidade humana leva a que fatores sexuais penetrem em toa'as as formas possiveis de relaçöes interpessoais formais ou informais e possam constituir, at, sob diversas configuraçōes éticas, estéticas e religiosas, determinados fatores inalienáveis da sociedade humana.

Ao se falar em sexualidade humana, fala-se de condições e manifestaçöes distintas para o homem e para a mulher, e se quisermos compreender como o poder do homem sobre a mulher vem se mantendo através dos tempos, distinguindo os papéis que cabem ao homem ou à mulher, verifica-se que há uma determinação histórico-social nas relações entre os sexos. 
Devido a questōes sociais, o surgimento da família monogâmica tomou-se símbolo da civilização e, nesse tipo de matrimônio, os laços conjugais são solidificados. Verifica-se que, mesmo na monogamia, a condição da fidelidade a um só parceiro só era verdadeira para a mulher. Isto não só se configura verdadeiro como normativo, quando, em 1804, o código Napoleônico sanciona o direito à infidelidade conjugal masculina, desde que a concubina não fosse trazida para o domicílio conjugal (6).

$O$ homem apoderou-se também da direção da ca. sa; a mulher viu-se degradada, convertida em servidora, em escrava da luxúria do homem, em simples instrumento de reprodução. Essa baixa condição da mulher... tem sido retocada, dissimulada e, em certos lugares, até revestida de formas de maior suavidade, mas de maneira alguma, suprimida (10).

Embora a divisão do trabalho dependa de outras causas que não a posição da mulher na sociedade, Engels (5) afirma que o maior poder do homem sobre a mulher, através dos tempos, surgiu na divisão do trabalho, e que a primeira divisão do trabalho é a que se fez entre o homem e a mulher para a procriação dos filhos, na monogamia.

Nos dias atuais, os casamentos se dão cada vez mais tarde, o início da vida sexual cada vez mais cedo e troca de parceiros sexuais cada vez com mais freqüência. Paralelamente a estes fenômenos, ocorre um aumento de doenças sexualmente transmissíveis em adolescentes e adultos jovens, vinculado à promiscuidade sexual, isto é, à parceria sexual múltipla.

Quando nos referimos à promiscuidade, vale a pena salientar que o comportamento social não é explicado pelo comportamento sexual, ou seja, não é a promiscuidade que degenera as relaçōes sociais. Contudo, só é possível compreender o comportamento sexual se observarmos que o modo de produção correspondente a uma sociedade $e$ as relaçóes sociais que sobre ele se constituem são responsáveis pela formaçâo de normas de comportamento também no campo da sexualidade (6).

Do mesmo modo que as normas de comportamento, as práticas de saúde se modificam e reestruturam conforme as relações sociais.

$O$ estabelecimento de relações de causa e efeito das doenças, intimamente relacionadas ao desenvolvimento da ciência e tecnologia, marca as diferentes concepções da saúde e da doença no decorrer da história.

A visão mágica da origem sobrenatural da doença é substituída pela nova dimensão que toma a saúde e a doença, com Hipócrates. Ele enfatiza a multicausalidade na gênese das doenças e refere-se à epilepsia, 
afirmando que a doença chamada sagrada... não é mais divina ou mais sagrada que qualquer outra doença; tem uma causa natural e sua origem supostamente divina reflete a ignorância humana, apud Scliar (24).

No século IV a.C., já existiam os grandes leprosários que, ao invés de hospitais, se constituíam em grandes depositários de doentes (24).

No século XVI, a lepra passou a ser menos diagnosticada $\mathrm{e}$, às doenças que atemorizam a Europa, há o acréscimo da sífilis. A seu respeito, nesse mesmo século, Fracastoro afirma: é contagiosa, mas só quando dois corpos entram em contato; o que acontece, especialmente, no ato sexual. Mesmo assim, por séculos, foi vista como puniçāo divina por pecados individuais. Coincidência ou não, era a época renascentista (24).

Só à época da Revolução Francesa, segundo Scliar (24), deu-se a concepção política entre saúde e sociedade, quando se aceita que a doença possa ser erradicada pela recuperação do corpo social. Baseado na divisão do trabalho, surge o conceito de corpo social, e aí aparece a saúde pública, que progrediu com o nascimento da epidemiologia e o desenvolvimento da microbiologia.

Mesmo com as evoluçōes no campo da saúde, as doenças que se situam no campo dos males sexualmente transmissíveis têm toda uma conotação moral que as envolve. Com a AIDS nāo foi diferente: estigmatizou-se o grupo homossexual, e há quem a veja, não muito raramente, como um castigo divino.

Levando-se em conta essas consideraçöes, podemos compreender que a AIDS é uma doença cuja história é um exemplo não só de investigação epidemiológica, como das complexas relaçōes entre doença $e$ sociedade (24).

\section{MATERIAL E MÉTODOS}

\section{Sujeitos}

A populaçăo pesquisada constitui-se de heterossexuais masculinos, não-pertencentes aos grupos clássicos de risco e com vida sexual ativa, ou seja, mantêm relaçōes sexuais.

\section{Variáveis}

a) Idade - esta variável não previamente delimitada porque, por se tratar de indivíduos com vida sexual ativa, os limites etários, apesar de previsíveis, não poderiam ser categoricamente estipulados. 
b) Estado Civil - nesta variável, seis situaçôes-base foram consideradas: solteiro; casado; com companheira; viúvo; separado; desquitado ou divorciado.

Esta separação foi elaborada com intenção ilustrativa, uma vez que as situaçōes podem se mesclar, mas fundamentalmente para investigar a possibilidade de correlação entre os dados pesquisados e estas condições.

c) Tamanho da amostra - foram aplicados questionários em 100 sujeitos, distribuídos, igualmente, em dez categorias sociais, como se segue: estudantes universitários, militares, estudantes de segundo grau, estudantes de primeiro grau, profissionais de saúde, profissionais liberais, trabalhadores no comércio, trabalhadores na indústria, trabalhadores em estabelecimentos bancários e profissionais de comunicação (rádio, jomal e televisão).

Se considerarmos que a populaçáo estimada de Campo Grande para 1989 é de 600.000 habitantes e que se estima que, destes, $30 \%$ são formados de população masculina de adultos, reconhecemos que a amostra não é representativa da população geral, do ponto de vista estatístico. A opção em subdividir a população investigada em dez grupos distintos se deu exatamente para que os dados, já que não preenchiam o requisito da representatividade, emergissem de um grupo aleatório e heterogêneo.

\section{Instrumento}

$O$ instrumento utilizado para a coleta de dados foi um questionário com questōes abertas e fechadas (anexo A), e a escolha do questionário, como instrumento, se deu pelo fato de que possibilita abrangência maior de informações, sem grande dispêndio de tempo, facilita a tabulação dos dados e favorece a padronização e comparação dos resultados, ao mesmo tempo em que garante o anonimato (2). O modelo final constou de cinco tópicos:

a) Vida sexual - composto de oito questões que serviram para delimitar os indivíduos que se enquadravam ou não nas categorias de risco, sendo o primeiro critério selecionar apenas os heterossexuais que compusessem a população-alvo; foram desprezados os questionários que năo preenchessem essa condição.

b) Condições pessoais - este item constou de cinco perguntas que contemplavam as condiçōes de risco em relação à $\mathrm{AIDS}$, sendo que qualquer resposta afirmativa neste item foi, também, condição excludente para a amostra.

c) Opinião sobre AIDS - este tópico contemplou duas perguntas abertas, ambas dizendo respeito a mudanças de comportamento sexual. Tanto a primeira, de conotação pessoal, quanto a segunda, dizendo respeito a heterossexuais masculinos, em geral, tiveram 
o objetivo de subsidiar a primeira hipótese de trabalho, a de que não está havendo mudanças de comportamento sexual da população-alvo, com vistas a evitar a disseminação da AIDS.

d) Campanhas educativas - o penúltimo item, com duas questōes, foi incluído no instrumento com o intento de colher a opinião da população investigada a respeito da eficácia das campanhas educativas, ao mesmo tempo em que permite a coleta de sugestōes acerca delas. Dessa forma buscou-se avaliar a segunda hipótese formulada (a baixa eficácia das campanhas educativas) e subsídios para a proposta de formulação de novas estratégias educacionais com relação à AIDS.

e) Situação atual da AIDS (em população heterossexual) - contendo uma única questão aberta, este item foi incluído no questionário devido à proposta de levantar informaçōes sobre a repercussāo social da AIDS, a fim de termos respaldo para as proposições finais.

\section{Coleta de Dados}

A aplicação do instrumento se deu individualmente, não havendo identificação do sujeito, exceto quando por manifestação espontânea do mesmo.

Todos os questionários foram aplicados no ambiente de trabalho dos sujeitos, pelo fato de ser esta a foma mais aleatória e a única possivel para a delimitação dos distintos grupos.

Após a explicação do objetivo da pesquisa e subseqüente à concordância do sujeito em participar, o instrumento foi lido para o entrevistado, assegurando-se a ele a garantia do anonimato.

\section{RESULTADOS}

Os resultados apresentados sob forma de quadros, correspondentes aos diversos tópicos e itens que compōem o questionário.

QUADRO II

Idade dos entrevistados

\begin{tabular}{cc}
\hline Grupo etário & Total \\
\hline $16-20$ & 23 \\
$21-25$ & 39 \\
$26-30$ & 24 \\
$31-35$ & 06 \\
$36-40$ & 07 \\
$41-45$ & 00 \\
$46-50$ & 00 \\
$51-55$ & 00 \\
$56-60$ & 01 \\
\hline Total & 100 \\
\hline
\end{tabular}

Cadernos de Saúde Pública, RJ, 7(1): 45-68, jan/mar, 1991. 
Observa-se que a idade média dos entrevistados gira em torno dos 25 anos $(28,4 \%)$ e, se considerarmos que a adolescência se estende até os 25 anos (8), temos então $52 \%$ dos indivíduos entrevistados na faixa de adolescência.

QUADRO III

Escolaridade

\begin{tabular}{lc}
\hline Nf́el & Total \\
\hline Primeiro grau incompleto & 07 \\
Primeiro grau completo & 16 \\
Segundo grau incompleto & 22 \\
Segundo grau completo & 27 \\
Terceiro grau incompleto & 15 \\
Terceiro grau completo & 13 \\
\hline Total & 100 \\
\hline
\end{tabular}

Dos entrevistados, $49 \%$ estão a nível de segundo grau, sendo que $23 \%$ encontram-se nos limites do primeiro grau, $15 \%$ com curso superior em andamento e $13 \%$ com terceiro grau concluído.

\section{QUADRO IV}

Estado civil/parceria

\begin{tabular}{lcccc}
\hline Estado Civil & $\begin{array}{c}\text { Parceria } \\
\text { fixa }\end{array}$ & $\begin{array}{c}\text { Parceria } \\
\text { variável }\end{array}$ & $\begin{array}{c}\text { Sem relaçäo } \\
\text { sexual }\end{array}$ & Total \\
\hline Solteiros & 29 & 25 & 06 & 60 \\
Casados & 19 & 05 & 00 & 24 \\
Com companheira & 10 & 01 & 00 & 11 \\
Viúvos & 01 & 00 & 00 & 01 \\
Separados & 00 & 00 & 00 & 00 \\
Desquitados/divorciados & 02 & 02 & 00 & 04 \\
\hline Total & 61 & 33 & 06 & 100 \\
\hline
\end{tabular}

O predomínio da parceria variável associou-se aos solteiros, como era de se esperar. 


\section{QUADRO V}

Parceria variável/uso de preservativos

\begin{tabular}{lcccccc}
\hline \multicolumn{7}{c}{ Estado Civil } \\
\hline Uso preserv. & Solt. & Cas. & C/comp. & Desq/div, & Vifivo & Total \\
\hline & & & & & & \\
Sim & 07 & 02 & 00 & 01 & 00 & 10 \\
Nåo & 08 & 03 & 01 & 00 & 00 & 12 \\
Às vezes & 10 & 00 & 00 & 01 & 00 & 11 \\
\hline Total & 25 & 05 & 01 & 02 & 00 & 33 \\
\hline
\end{tabular}

Entre os solteiros com parceria variável, metade dos entrevistados não usa preservativos. Os que têm parceria fixa não foram observados neste quadro, devido ao nāo-enquadramento na relação tisco/promiscuidade.

\section{QUADRO VI \\ Justificativa quanto ao usc de preservativos/parceria variável}



Os que responderam afirmativamente ao uso de preservativos e que possuem parceria variável $(69,7 \%)$ não têm preocupaçáo com transmissăo de doenças e constituem $23 \%$ da população entrevistada total (100).

Cadernos de Saude Pública, RJ, 7(1): 45-68, jan/mar, 1991. 
Vida sexual

Manutençăo da atividade sexual

Total

Mantém relaçöes sexuais

94

Não mantém relaçōes sexuais

06*

- Desses seis elementos, tres já tiveram experiencias sexuais anteriores e tres nso têm experiencir sexual presente ou passada, sendo que todos alegaram que tal atitude se deve a questoes de prática religiosa presente.

\section{Total}

\section{QUADRO VIII}

\section{Freqüência das relaçōes sexuais}

\begin{tabular}{lc}
\hline Número de vezes & Total \\
\hline De 1 a 3 vezes por semana & 61 \\
De 4 a mais vezes por semana & 08 \\
De 1 a 3 vezes por més & 13 \\
De 1 a 3 vezes por ano & 00 \\
De 4 a mais vezes por ano & 03 \\
Năo responderam & 09 \\
Nåo mantém relaçöes sexuais & 06 \\
\hline Total & 100 \\
\hline
\end{tabular}

\section{QUADRO IX}

\section{Conduta sexual}

\begin{tabular}{lc}
\hline Conduta sexual & Total \\
\hline Heterossexual & 94 \\
Homossexual & 00 \\
Bissexual & $06^{*}$ \\
\hline Total & 100 \\
\hline
\end{tabular}

- Todos os seis elementos que afirmaram ter tido contatos bisso xuais enfatizaram que 0 contato com a pessoa do mesmo sexo se deu uma única vez e há mais de seis anos. Devido a isso, nåo foram considerados como tendo fator de risco. 


\section{QUADRO X}

Condiçōes pessoais/componentes de risco

\begin{tabular}{ll}
\hline Componentes de risco & Total \\
\hline Usuários de drogas injetáveis & 03 \\
Receptores de sangue nos ultimos seis anos & 00 \\
Usuários de hemoderivados & 00 \\
Hemofálicos & 00 \\
Parceria sabidamente de risco & $08^{*}$ \\
\hline Total & 11 \\
\hline
\end{tabular}

QUADRO XI

Mudança de comportamento sexual após a AIDS

\begin{tabular}{lcccc}
\hline $\begin{array}{l}\text { Quanto a } \\
\text { Parceria }\end{array}$ & Fixa & Variâvel & $\begin{array}{c}\text { Sem } \\
\text { Parceria }\end{array}$ & Total \\
\hline Sim & 34 & 26 & 00 & 60 \\
Nåo & 25 & 07 & 06 & 38 \\
\hline Total & 59 & 33 & 06 & 98 \\
\hline
\end{tabular}




\section{QUADRO XII}

Causas de mudança ou não de comportamento sexual após a AIDS

\begin{tabular}{|c|c|c|}
\hline Mudança Pessoal & Justificativa & Total \\
\hline \multirow[t]{9}{*}{ Sim } & Passou a selecionar parceiras & 22 \\
\hline & Diminuiu o nfimero de parceiras & 13 \\
\hline & Dizse consciente dos riscos & 05 \\
\hline & Passou a evitar relaçōes com prostitutas & 06 \\
\hline & Diminuiu o número de relaçöes sexuais & 05 \\
\hline & Adotou o uso de preservativos & 04 \\
\hline & Passou a evitar o coito anal & 02 \\
\hline & Deixou de manter relaçőes extraconjugais & 02 \\
\hline & NÉ justificou & 01 \\
\hline \multirow[t]{6}{*}{ NE⿷ } & Tem parceria ínica & 21 \\
\hline & Nfo esta preocupado com a AIDS & 06 \\
\hline & Tem relaçóes sexuais com pessoas conhecidas & 04 \\
\hline & NẼ mantem relaçöes sexuais & 06 \\
\hline & NEo justificou & 01 \\
\hline & Total & 98 \\
\hline
\end{tabular}

\section{QUADRO XIII}

Mudança admitida nos relacionamentos sexuais dos homens, de forma geral, após a AIDS

\begin{tabular}{cc}
\hline Mudança Admitida & Total \\
\hline Sim & 82 \\
N\&o & 16 \\
\hline Total & 98 \\
\hline
\end{tabular}




\section{QUADRO XIV}

Causas de mudanças ou não admitidas nos relacionamentos sexuais de heterossexuais

\begin{tabular}{|c|c|c|}
\hline Mudança admitida & Justificativa & Total \\
\hline \multirow[t]{9}{*}{$\operatorname{Sim}$} & Os homens têm medo de adquirir AIDS & 43 \\
\hline & Os homens passaram a selecionar parceiras & 11 \\
\hline & Houve restrição ao número de parceiras & 10 \\
\hline & Passaram a evitar relaçōes homossexuais & 07 \\
\hline & Deixaram de ter relaçöes sexuais com prostitutas & 06 \\
\hline & Evitam ter relaçöes extraconjugais, pensando & \\
\hline & na saúde da famflia & 03 \\
\hline & Passaram a usar preservativos & 01 \\
\hline & Nāo justificou. & 01 \\
\hline \multirow[t]{5}{*}{ Não } & Os homens não acreditam em AIDS & 08 \\
\hline & É difficil resistir a uma relação sexual & 05 \\
\hline & Não conhece ninguém que passou a usar preservativo & 01 \\
\hline & Os homossexuais são que mudaram & 01 \\
\hline & Não justificou & 01 \\
\hline Total & & 98 \\
\hline
\end{tabular}

\section{QUADRO XV}

Avaliação dos objetivos das campanhas de educação sanitária - AIDS

\begin{tabular}{clr}
\hline Objetivos Alcançados & Justificativa & Total \\
\hline Sim & Servem de aierta à população & 10 \\
& Esclarecem as pessoas & 18 \\
& As pessoas estão mudando os hábitos & 20 \\
& Trazem medo e as pessoas mudam & 06 \\
& Esclarecem parcialmente & 05 \\
& Apenas os adultos estäo sendo atingidos & 02 \\
& Conscientizam as pessoas & 01 \\
& Informam pouco & 07 \\
& Causam medo e esclarecem pouco & 05 \\
& São dirigidas às camadas mais elevadas culturaimente & 06 \\
& A linguagem é pouco acessível & 03 \\
& O uso de metáforas torna as campanhas elitizadas & 04 \\
& São preconceituosas & 02 \\
& Năo provocam mudanças significativas & 07 \\
\hline
\end{tabular}




\section{QUADRO XVI}

Sugestōes para melhorar o nível de informação da população a respeito da AIDS

\begin{tabular}{clc}
\hline $\begin{array}{l}\text { Validade das } \\
\text { Campanhas }\end{array}$ & Sugestōes & Total \\
\hline \multirow{2}{*}{ Sim } & Mensagens dirigidas especificamente aos jovens & \\
& Devem ser mais esclarecedoras e menos moralizantes & 05 \\
& Campanhas menos alarmistas & 09 \\
& Divulgaçäo dirigida a pessoas de baixo nfvel cultural & 13 \\
& Linguagem mais acessível & 07 \\
& Palestras e seminários dirigidos ao público em geral & 10 \\
& Palestras nas comunidades e empresas & 06 \\
& Divulgação, pela TV, de pesquisas recentes & 08 \\
& Palestras em colégios & 02 \\
Năo & Campanhas voltadas para os jovens e adolescentes & 04 \\
& Mais clareza quanto aos riscos e formas de transmissão & 06 \\
& Informações que conscientizem sem causar medo & 06 \\
& Campanhas dirigidas às camadas mais baixas da população & 07 \\
Não responderam & Mensagens falando sobre o que é a doença & 04 \\
& & 07 \\
\hline Total & & 04 \\
\hline
\end{tabular}

\section{QUADRO XVII}

Causas admitidas para o aumento do número de casos de ADS na população heterossexual

Manutençåo dos hábitos sexuais de risco devido à deficiente informação 51

Năo acreditam ou năo estão conscientes dos riscos da AIDS 19

$\begin{array}{ll}\text { Uso de drogas injetáveis } & 12\end{array}$

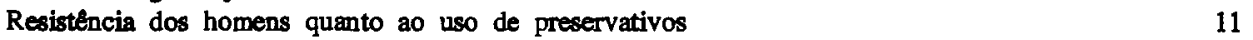

$\begin{array}{ll}\text { Formas desconhecidas de transmissão } & 03\end{array}$

Descaso do governo com relação aos transmissores da doença 02 


\section{DISCUSSÃO}

Este capítulo destina-se à análise dos resultados obtidos, destacando-se os dados considerados como fundamentais.

Idade - Cabe salientar que se trata de população jovem, visto que $86 \%$ dos entrevistados situam-se nos limites etários compreendidos entre 17 e 30 anos.

Nível de Escolaridade - verifica-se que não há correlação entre o grau de instrução e a estrutura da resposta, ressaltando apenas que elas se diferenciam na forma de serem expressas, mas seu conteúdo não sofre na qualidade.

Condição Civil - neste item pudemos observar que $71 \%$ dos entrevistados não têm vínculo legal (casamento) com as parceiras, embora mais da metade desse grupo mencione ter parceira fixa e única. Do total de entrevistados, 33 têm parceiras variáveis, constituindo-se em grupo que foi observado quanto ao uso de preservativos no que diz respeito à forma de prevenção eleita.

Parceria Variável/Uso de Preservativos - partindo do princípio que a populaçāo com parceria variável é objeto maior de observação por estar mais sujeita aos riscos em relaçăo à AIDS, procuramos investigar 0 uso de preservativos nesse grupo. Isso se deve ao fato de que este é o método mais estimulado como medida de prevenção e também o mais eficiente em populaçōes com vida sexual ativa e sem parceria fixa.

Responderam $\operatorname{sim} 30,3 \%$ dos pertencentes ao grupo; $36,3 \%$ responderam não e $33,4 \%$ disseram às vezes.

O grupo que respondeu afirmativamente justificou em $80 \%$ que seu uso se dá como forma de prevenção às doenças sexualmente transmissíveis, $10 \%$ como método contraceptivo e $10 \%$ não justificaram.

Dos que responderam às vezes, apenas $10 \%$ o fazem como forma de prevenção às DSTs. Dos outros $90 \%, 20 \%$ os usam como método contraceptivo, utilizando-os apenas quando as parceiras correm risco de ficarem grávidas. Como o uso ocasional de preservativos não se constitui medida eficiente de prevenção, esses e mais os $70 \%$ do grupo foram reunidos aos que responderam não ao uso de preservativo, ficando, dessa forma, $69,7 \%$ dos entrevistados com parceria variável distanciados das formas de prevenção não só da AIDS como de todas as doenças sexualmente transmissíveis.

Cabe ainda a ressalva de que 56,5\% desse grupo mencionaram não terem preocupação com a transmissão de doenças por via sexual, dizendo que até pensam na AIDS, mas preferem acreditar que a doença acontece com os outros mas não com eles mesmos. 
Componentes de Risco - indagamos quanto às condições clássicas de risco, com o propósito semelhante ao item anterior, ou seja, excluir os indivíduos da amostra. Houve menção de três sujeitos quanto ao uso de drogas injetáveis sem indicação terapêtutica, sendo que dois deles, um com 36 anos e outro com 29 , disseram que tal procedimento ocorreu por volta dos 17-18 anos, não sendo, portanto, excluídos da amostra.

No que diz respeito ao fato de terem tido parceria de risco, oito disseram ter tido relaçōes sexuais com usuárias de drogas, sendo que apenas duas o faziam de forma injetável. Como os contatos se deram em prazo inferior a seis anos, o dado foi suficiente para excluí-los da amostra. A partir daí, ficamos com as opiniōes de 98 sujeitos.

\section{A AIDS PROVOCOU ALGUMA MUDANÇA NOS SEUS RELACIONAMENTOS SEXUAIS?}

A essa pergunta, $61,2 \%$ responderam afirmativamente, sendo que apenas $46,6 \%$ desse grupo realmente optaram por medidas que são eficientes quanto à prevenção, ou seja, passaram a selecionar parceiras e/ou optaram pelo uso de preservativos. Justificativas como: diminuição do número de parceiras, eliminação dos coitos anais, de relações sexuais com prostitutas, ou simples diminuição do número de relaçốes sexuais, são medidas que, apenas de forma parcial, são eficientes.

Dos que responderam não à pergunta, $55,2 \%$ não mantêm relações com parceiras variáveis, sendo, portanto, grupo não-sujeito aos riscos clássicos. Dos $44,8 \%$ restantes, $15 \%$ não mantêm relações sexuais por questōes religiosas, estando eximidos dos grupos de risco por contaminação via sexual. Logo, se considerarmos que $28,9 \%$ não têm preocupação ou não acreditam na AIDS ou seus riscos, agrupados aos $53,4 \%$ daqueles cujas medidas preventivas são ineficazes, temos um grupo composto por $47 \%$ do total dos entrevistados que podem estar expostos à infecção.

Grande parte dos heterossexuais entrevistados, $83,6 \%$, acreditam que os homens mudaram seu comportamento sexual, mas a justificativa alegada (53\%) é a de que a AIDS provoca medo e isso os faz pensar que os hábitos sexuais foram modificados.

CAMPANHAS EDUCATIVAS - quando indagados acerca da eficiência das campanhas educativas, 64 indivíduos afirmaram que elas são parcialmente esclarecedoras, isto porque não atingem às camadas mais baixas da população devido a mensagens elitizadas, nem tampouco aos adolescentes, pelo conteúdo pouco acessível. Com relação às respostas negativas a essa pergunta, as justificativas são críticas no sentido de 
que as campanhas atuais causam mais medo que informação, tanto pelo conteúdo alarmista quanto pelo teor moralizante.

Quando inquiridos acerca das sugestões para melhorar o nível de informação da população, tanto os que disseram sim quanto os que não acreditam na eficiência das campanhas, enfatizaram o aspecto da necessidade da informação ser mais precisa e direcionada a grupos etários e sócio-culturais distintos, devendo-se investir em palestras ao público, nas empresas, escolas e comunidade, de forma constante.

Diante da constataçáo do aumento de casos de AIDS em população heterossexual, as opiniōes se dividiram e se mesclaram em dois aspectos básicos: além dos homens estarem pouco informados a ponto de não acreditarem na doença ou nāo estarem conscientes dos riscos, existe a resistência em mudar os hábitos sexuais, tais como usar preservativos em todas as relações pouco seguras e/ou desistir de uma relaçāo sexual pela possibilidade de vir a por em risco sua saúde.

\section{CONCLUSÃO}

$O$ questionamento inicial que se fundamentava num dado concreto - o aumento de casos de AIDS em heterossexuais masculinos - levantou a hipótese de que as campanhas educativas não estavam atingindo o objetivo de esclarecer a população acerca da doença e riscos, sensibilizando-a quanto à importância das medidas preventivas individuais.

Considerando que os heterossexuais masculinos avaliados não se enquadram nas categorias de risco e observando que a incidência de casos de AIDS, nessa população, vem sofrendo aumento progressivo, partimos do pressuposto que o acesso às informaçōes veiculadas nẫo se constitui em instrumento ainda eficiente para aquele grupo, na medida em que não se verificaram modificaçōes de atitudes em cerca de metade dos entrevistados.

Dos dados obtidos, porém, verificamos que $61,2 \%$ da população investigada referiram haver modificado seus hábitos sexuais devido à AIDS. À primeira vista essa informação parecia rejeitar a hipótese de que os heterossexuais nāo haviam adotado medidas eficazes contra a possibilidade de infecção pelo HIV.

Entretanto, analisando de que forma se deram as mudanças referidas, verificamos que mais da metade dessa população, essencialmente jovem, optou por medidas ineficazes à prevenção da AIDS.

Apesar de terem acesso às informaçōes, ficou patente que existem hábitos sociais arraigados que vêm de encontro a medidas preventivas, tais como o uso de preservativos e/ou restrição de multiplicidade de 
parceiras. Curiosamente, parece que o instinto de preservação da vida, nesse momento, não se sobrepōe às atitudes que podem colocá-la em risco.

Acreditamos que a questão da informação clara e direta é o que se constitui no fator que merece atenção específica. Cabe-nos pesquisar, delimitar e divulgar as formas adequadas de levar à população os conhecimentos necessários para que, através de mudanças de comportamentos individuais, embasados em decisões conscientes, possa se diminuir ou até mesmo controlar o processo da disseminação do HIV.

Mesmo considerando que o trabalho se desenvolveu em uma região com particularidades sócio-culturais evidentes, acreditamos que o mesmo possa se constituir em referencial para pesquisas científicas mais estratificadas e de valor estatístico mais abrangente, com diferenciação de propostas de campanhas até, possivelmente, regionais. Somente dessa forma poderemos realizar um trabalho proficuo sedimentado em dados reais de natureza epidemiológica e sócio-cultural tão diversificados, num país de dimensões continentais, como o Brasil.

Conscientes da fundamental importância do processo educativo no que concerne à prevenção da AIDS, dada a inexistência de recursos terapêuticos e a dimensão epidêmica da doença, fica a certeza de que reestruturaçōes são necessárias no conteúdo e na forma das campanhas, devendo-se, para isto, priorizar investimentos concernentes à educação sanitária da população.

Tal processo, contudo, só se tornará viável se considerarmos a confluência de fatores histórico-sociais, da sexualidade e da saúde. Caso contrário, o nosso discurso será demagógico e dissociado das nossas reais possibilidades de atuação visando a modificação da realidade.

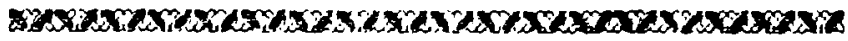

Taking into account the educational campaigns implemented in Campo Grande (Mato Grosso do Sul State, Brazil), the purpose of this study was to learn the perceptions of a non-risk of AIDS sample of 100 males about the disease and how it has changed their sexual and social behaviors. Data was collected during January 2 and February 14, 1989 and 98 questionnaires were used for the analyses. Sixty per cent of the respondents declared that they have changed their sexual habits, although more than 50\% selected inefficient prevention methods. 
The study indicates that there are social and cultural patterns which strongly determine rejection of effective prevention methods, such as: use of condoms or reduced numbers of partners. The conclusions emphasize the importance of redesigning the contents and formats of AIDS educational programs for the population based on scientific research.

\section{REFERÊNCIAS BIBLIOGRÁFICAS}

1. BANDER, Mike P. - Psicologia da Comunidade. Rio de Janeiro, Zahar Editores, 1978.

2. BARROS, Aidil J. P. \& LEHFELD, Neide A. S. - Fundamentos de Metodologia. São Paulo, McGrow-Hill Editora, 1986.

3. CORDEIRO, Hésio - A Indústria da Saúde no Brasil. Rio de Janeiro, Ed. Graal, 1985.

4. COSTA, Moacir - Sexualidade em Macho, Masculino, Homem. São Paulo, L\&PM Editores Ltda., 1986.

5. ENGELS, Friedrich - A Dialética da Natureza. São Paulo, Editora Paz e Terra, 1985.

6. ENGELS, Friedrich - A Origem da Famllia, da Propriedade Privada e do Estado. Rio de Janeiro, Editora Civilizaçāo Brasileira, 1978.

7. EVERS, T. - Identidade: a face oculta dos movimentos sociais. São Paulo, Novos Estudos, 1984.

8. FITZGERALD, Hiram \& STRONNEM, Ellen - Psicologia do Desenvolvimento. São Paulo, Editora Brasiliense, 1972.

9. GABEIRA, Fernando - Machismo em Macho, Masculino, Ho mem. Săo Paulo, L\&PM Editores, Ltda, 1986.

10. GOODE, William J. \& HATT, Paul K. - Métodos em Pesquisa Social. São Paulo, Companhia Editora Nacional, 1974.

11. HIEBSCH, Hans \& VOR WERG, Manfred. Psicologia Social e Marxismo. Portugal, Novo Curso Editoras, 1984.

12. KONDER, Leandro - $O$ que é dialética. São Paulo, Ed. Brasiliensie, 1984.

13. LANE, Silvia M. T. \& CODO, Wanderley (org). O Homem em Movimento. São Paulo, Editora Brasiliense, 1987.

14. MINISTÉRIO DA SAÚDE - AIDS: Boletim Epidemiolbgico - Ano III - N: 02. Fevereiro, 1990.

15. MINISTÉRIO DA SAÚdE - Boletim do Serviço Técnico de Terminologia da Organização Mundial da Saúde. Centro Brasileiro de Classificaçäo de Doenças, Vol. 7. N: 03, Setembro a Dezembro, 1986.

16. MINISTÉRIC DA SAÚDE - Guia para Controle de Doenças Sexualmente Transmissiveis, 1984.

17. MINISTÉRIO DA SAÚDE - Recomendaçōes para Prevenção e Controle da Infecção pelo Vfrus HIV (SIDA/AIDS), 1978.

18. MINISTÉRIO DA SAÚDE - Vigilância Epidemiológica Abordagem de conceitos básicos relativos à Vigilância, 1988.

19. MIRANDA SÁ, Luis S. - Psicopatologia e Propedêutica. São Paulo, Livraria Atheneu, 1984.

Cadernos de Saúde Páblica, RJ, 7(1):45-68, jan/mar, 1991. 
20. MORAES, Maurilton - Sexo: O Macho e o Poder. Rio Grande do Norte, Nossa. Editora, 1984.

21. MOSCOVICI, S. - A representação social da Psicanálise. Rio de Janeiro, Zahar Editores, 1978.

22. PETROVSKI, A. V. - Personalidad, Actividad y Colectividad. Buenos Aires, Editorial Cartago, 1984.

23. RUIZ, João A. - A Metodologia Cientifica. São Paulo, Editora Atlas, 1986.

24. SCLIAR, Moacyr - Do Mágico ao Social. Rio Grande do Sul, L\&PM Editores Ltda, 1987.

25. THE PANOS INSTITUTE - SIDA/AIDS e o Terceiro Mundo, Distrito Federal, 1987. 